\title{
Inadequate treatment of ventilator-associated and hospital-acquired pneumonia: Risk factors and impact on outcomes
}

\author{
Nihal Piskin ${ }^{*}$, Hande Aydemir ${ }^{1}$, Nefise Oztoprak ${ }^{2}$, Deniz Akduman ${ }^{1}$, Fusun Comert ${ }^{3}$, Furuzan Kokturk ${ }^{4}$ \\ and Guven Celebi ${ }^{1}$
}

\begin{abstract}
Background: Initial antimicrobial therapy $(A B)$ is an important determinant of clinical outcome in patients with severe infections as pneumonia, however well-conducted studies regarding prognostic impact of inadequate initial $A B$ in patients who are not undergoing mechanical ventilation (MV) are lacking. In this study we aimed to identify the risk factors for inadequate initial $A B$ and to determine its subsequent impact on outcomes in both ventilator associated pneumonia (VAP) and hospital acquired pneumonia (HAP).
\end{abstract}

Methods: We retrospectively studied the accuracy of initial $A B$ in patients with pneumonia in a university hospital in Turkey. A total of 218 patients with HAP and 130 patients with VAP were included. For each patient clinical, radiological and microbiological data were collected. Stepwise multivariate logistic regression analysis was used for risk factor analysis. Survival analysis was performed by using Kaplan-Meier method with Log-rank test.

Results: Sixty six percent of patients in VAP group and $41.3 \%$ of patients in HAP group received inadequate initial $A B$. Multiple logistic regression analysis revealed that the risk factors for inadequate initial AB in HAP patients were; late-onset HAP $(\mathrm{OR}=2.35(95 \% \mathrm{Cl}, 1.05-5.22 ; \mathrm{p}=0.037)$ and APACHE II score at onset of HAP $(\mathrm{OR}=1.06(95 \% \mathrm{Cl}$, 1.01-1.12); $p=0.018)$. In VAP patients; antibiotic usage in the previous three months ( $\mathrm{OR}=3.16(95 \% \mathrm{Cl}, 1.27-7.81)$; $p=0.013)$ and admission to a surgical unit $(O R=2.9(95 \% C l, 1.17-7.19) ; p=0.022)$ were found to be independent risk factors for inadequate initial $\mathrm{AB}$. No statistically significant difference in crude hospital mortality and 28-day mortality was observed between the treatment groups in both VAP and HAP. However we showed a significant increase in length of hospital stay, duration of mechanical ventilation and a prolonged clinical resolution in the inadequate $A B$ group in both VAP and HAP.

Conclusion: Our data suggests that the risk factors for inadequate initial $A B$ are indirectly associated with the acquisition of resistant bacteria for both VAP and HAP. Although we could not find a positive correlation between adequate initial $A B$ and survival; empirical $A B$ with a broad spectrum should be initiated promptly to improve secondary outcomes.

\section{Background}

Nosocomial pneumonia, which is usually defined as hospital-acquired pneumonia (HAP), is the second most frequent nosocomial infection but the first in terms of morbidity, mortality and cost. It occurs in $8-20 \%$ of intensive care unit (ICU) patients, with an increased frequency and mortality if the patients are mechanically

\footnotetext{
* Correspondence: nihal_piskin@yahoo.com

'Departments of Infectious Diseases and Clinical Microbiology, School of Medicine, Zonguldak Bulent Ecevit University, Zonguldak, Turkey

Full list of author information is available at the end of the article
}

ventilated [1-4]. Over the past decade, several risk factors associated with mortality have been detected in HAP and ventilator-associated pneumonia (VAP). One of the most consistent and evident prognostic factor throughout the literature is the accuracy of initial antibiotic treatment $(\mathrm{AB})$. By contrast, early aggressive therapy with adequate broad-spectrum regimens that optimize therapy against the likely pathogens is associated with lower mortality rates and shorter hospital stay [4-8]. However, despite numerious studies some 
controversies continue to exist about the genuine prognostic impact of initial AB [9-14].

In recent years, international societies and most recently, the American Thoracic Society jointly with the Infectious Diseases Society of America, have developed guidelines for the management of HAP and VAP $[2,3]$. In spite of the presence of practice guidelines, the percentage of inadequate $A B$ varies in the literature from $10 \%$ to $73 \%$ [8-11,13-18]. The presence of multidrugresistant bacteria is the primary reason that patients with VAP and HAP receive inadequate $A B$ [5], however other factors that contribute to inadequate $A B$ are not well defined. Therefore, we aimed to identify the possible risk factors for inadequate initial $\mathrm{AB}$ in both HAP and VAP and to determine its subsequent impact on outcomes.

\section{Methods}

\section{Patients and setting}

This retrospective cohort study was conducted at Zonguldak Bulent Ecevit University Hospital, a 524 bed referral and tertiary hospital, from January 2005 to January 2008. Patients were enrolled in the study if they were $>16$ years of age and diagnosed with VAP or HAP irrespective of the diagnosis at admission. Only the first episode of pneumonia was taken into account and no community acquired pneumonia cases were included. The study was approved by the Zonguldak Bulent Ecevit University Hospital Ethics Committee. The need for informed consent was waived due to the retrospective observational nature of the study.

For each patient clinical, radiological and microbiological data were collected. The following characteristics were retrieved from patient records: age, sex, underlying diseases, antibiotic usage in the previous three months, Acute Physiological Score Chronic Health Evaluation (APACHE) II at onset of pneumonia, length of hospital and ICU stays, presence of invasive procedures, duration of mechanical ventilation, presence of an other site infection, microbiological culture results, fever and/or other clinical symptoms resolution dates and mortality.

\section{Definitions}

Hospital-acquired pneumonia was diagnosed on the basis of Centers for Disease Control and Prevention clinical criteria [19]. Pneumonia was considered ventilator associated when it occurred 48 hours after starting mechanical ventilation and it was known to have not been incubating before the initiation of MV. Pneumonia was defined as early-onset if it started within 4 days of admission, in accordance with the American Thoracic Society/Infectious Disease Society of America guidelines $[2,3]$. Quantitative cultures of respiratory samples obtained at the time of diagnosis were used to diagnose pneumonia. Inadequate $A B$ was defined as, at least one bacterial isolate not covered by any initial antibiotic, or when the pathogen was resistant to all initial empiric antimicrobial agents. In culture negative cases, patients' records were evaluated and appropriateness of $A B$ was decided according to resolution of clinical and laboratory signs of pneumonia with the initial regimen that had been pursued or changed. AB was modified as soon as susceptibility testing results were available or if the clinical and radiological signs of pneumonia did not improve, mainly within $48-72$ hours. The total number of deaths within 28 days after the onset of pneumonia and during hospitalization were defined as 28-day mortality and in-hospital mortality respectively.

\section{Microbiological data}

Microbiological data for the patients was obtained from cultures of sputum, transendotracheal aspirates (TA), blood, pleural fluids and bronchoalveolar lavage (BAL) fluids. The bacteriological diagnosis required the following criteria: Sputum and TA cultures growing $\geq 10^{5}$ colony-forming units $(\mathrm{cfu}) / \mathrm{ml}$ of bacteria, BAL cultures growing $10^{4} \mathrm{cfu} / \mathrm{ml}$ of bacteria, blood or pleural fluid cultures revealing the same pathogen with the respiratory samples. Appropriate specimens of sputum and TA to be taken into consideration for diagnostic testing required a white blood cell count of $>25$ and $<10$ epithelial cells per low-power examination field. Bacterial identification and susceptibility testing were performed by standard methods. The identification of "mouth flora" was considered as culture negative.

\section{Statistical analysis}

Statistical analysis was performed with SPSS 18.0 software (SPSS, Inc., Chicago, IL, USA). Continuous variables were expressed as mean \pm standard deviation and categorical variables as numbers and percentages. Continuous variables were compared with the Independent Sample T test or Mann-Whitney $U$ test and categorical variables were compared using Pearson's Chi-square test or Fisher's Exact Chi-square test. A $P$ value of less than 0.05 was considered statistically significant for all tests. Forward stepwise logistic regression model was performed to assess the independent risk factors for inadequate initial antibiotic treatment in both HAP and VAP patients. Survival analysis was performed using KaplanMeier method with Log-rank test.

\section{Results}

During the study period 348 patients met the inclusion criteria in whom 218 patients developed HAP and 130 patients developed VAP. The mean age of the patients was $63.56 \pm 15.17$ and $62.9 \%$ were male. The most frequent admission diagnoses included respiratory diseases (namely COPD, ARDS or acute respiratory failure) 
(32.3\%), neurological diseases (17.7\%), malignancy (13.1\%) in VAP patients and respiratory diseases (34.9\%), malignancy $(20.2 \%)$ and metabolic diseases (27.1\%) in HAP patients. Eighty six (66\%) patients in VAP group and 90 (41.3\%) patients in HAP group received inadequate initial AB. Characteristics of patients with HAP and VAP with regard to the adequacy of empirical $A B$ are summarized in Tables 1 and 2 respectively. Age, sex, comorbidities and admission diagnosis were not statistically different between treatment groups in either HAP or VAP patients.

In all VAP cases TA and/or BAL cultures were performed. While for the HAP group, TA cultures were performed in 45 patients and BAL cultures were performed in 7 patients, the remaining samples were all sputum cultures. Of the 130 patients with VAP, 13 (10\%) were culture negative, eight patients $(6.1 \%)$ had polymicrobial infection and $92(78.6 \%)$ patients were infected by a multi-drug resistant pathogen. The number of cultures which grew non-fermenting gram-negative bacilli was higher in the inadequate $\mathrm{AB}$ group but the difference was not statistically significant (Table 3). Of the 218 patients with HAP, 124 (56.9\%) were culture negative, nine patients (4.1\%) had polymicrobial infection and 67 (30.7\%) patients were infected by a multi-drug resistant pathogen. Totally 103 pathogens were isolated from 94 patients. The isolated pathogens are presented in Table 3.
The regimens of empiric antibiotics are summarized in Table 4. Thirty three (25.4\%) patients in VAP group and $13(5.9 \%)$ patients in HAP group received an antibiotic combination with a glycopeptide antibiotic. Among the patients who received inadequate initial $A B$, antibiotic therapy was modified $4.84 \pm 2.49$ and $3.80 \pm$ 2.49 days after the onset of pneumonia in VAP and HAP patients respectively.

As the number of culture negative pneumonias were high especially in the HAP group, we also performed the analysis in "culture positive patients only" in both HAP and VAP to determine whether the risk factors differed based on culture positivity. The results are presented in Table 5.

To define the independent risk factors for inadequate initial $\mathrm{AB}$ in both HAP and VAP; multiple logistic regression analysis was performed and age, gender, type of ICU and/or general ward, presence of underlying diseases, presence of central venous catheterization and mechanical ventilation, duration of intubation (for VAP patients only), duration of hospitalization before onset of pneumonia, previous antibiotic usage in the previous three months, APACHE II score at onset of pneumonia, diagnosis of pneumonia (late-onset) and presence of multi-drug resistant bacteria were included to the model. There were no multicolinearity in the variables included

Table 1 Characteristics of $\mathbf{2 1 8}$ patients with HAP with regard to the adequacy of empirical antibiotic treatment

\begin{tabular}{|c|c|c|c|}
\hline Characteristics & Adequate treatment $n=128$ & Inadequate treatment $\mathrm{n}=\mathbf{9 0}$ & $\mathrm{p}$ \\
\hline Age (years) & $61.84 \pm 14.66$ & $64.44 \pm 13.49$ & 0.189 \\
\hline Sex (male) & $84(65.6)$ & $58(64.4)$ & 0.857 \\
\hline Surgical unit & $24(68.6)$ & $11(31.4)$ & 0.269 \\
\hline \multicolumn{4}{|l|}{ Underlying diseases } \\
\hline Diabetes mellitus & $26(20.3)$ & $14(15.6)$ & 0.474 \\
\hline COPD & $32(25.0)$ & $19(21.1)$ & 0.613 \\
\hline Chronic renal failure & $14(10.9)$ & $10(11.1)$ & 1.000 \\
\hline Congestive heart failure & $15(11.7)$ & $16(17.8)$ & 0.287 \\
\hline Cerebrovascular disease & $7(5.5)$ & $10(11.1)$ & 0.203 \\
\hline Malignancy & $24(18.8)$ & $22(24.4)$ & 0.398 \\
\hline Central venous catheterization & $37(28.9)$ & $35(38.9)$ & 0.123 \\
\hline Urinary catheterization & $88(68.8)$ & $66(73.3)$ & 0.464 \\
\hline Late-onset pneumonia & $78(60.9)$ & $72(80.0)$ & 0.003 \\
\hline Acquisition of other site infection & $21(16.4)$ & $20(22.2)$ & 0.365 \\
\hline Previous antibiotic usage & $42(32.8)$ & $34(37.8)$ & 0.449 \\
\hline Culture proven pneumonia & $43(33.6)$ & $51(56.7)$ & 0.001 \\
\hline MDR bacteria & $29(22.7)$ & $38(42.2)$ & 0.002 \\
\hline Polymicrobial etiology & $1(0.8)$ & $8(8.9)$ & 0.004 \\
\hline Length of stay before HAP & $7.09 \pm 5.07$ & $8.52 \pm 5.26$ & 0.003 \\
\hline APACHE I| score & $12.68 \pm 5.79$ & $14.63 \pm 6.59$ & 0.024 \\
\hline
\end{tabular}


Table 2 Characteristics of 130 patients with VAP with regard to the adequacy of empirical antibiotic treatment

\begin{tabular}{|c|c|c|c|}
\hline Characteristics & Adequate treatment $n=44$ & Inadequate treatment $\mathbf{n}=\mathbf{8 6}$ & $\mathbf{p}$ \\
\hline Age (years) & $65.64 \pm 16.42$ & $64.15 \pm 16.83$ & 0.628 \\
\hline Sex (male) & $29(65.9)$ & $48(55.8)$ & 0.358 \\
\hline Surgical unit & $22(45.8)$ & $26(54.2)$ & 0.044 \\
\hline \multicolumn{4}{|l|}{ Underlying diseases } \\
\hline Diabetes mellitus & $6(13.6)$ & $13(15.1)$ & 1.000 \\
\hline COPD & 15(34.1) & $18(20.9)$ & 0.156 \\
\hline Chronic renal failure & $1(2.3)$ & $4(4.7)$ & 0.672 \\
\hline Congestive heart failure & $7(15.9)$ & $15(17.4)$ & 1.000 \\
\hline Cerebrovascular disease & $5(11.4)$ & $16(18.6)$ & 0.418 \\
\hline Malignancy & $6(13.6)$ & $13(15.1)$ & 1.000 \\
\hline Central venous catheterization & $34(77.3)$ & $62(72.1)$ & 0.671 \\
\hline Urinary catheterization & $43(97.7)$ & $84(97.7)$ & 1.000 \\
\hline Late-onset VAP & $36(81.8)$ & $75(87.2)$ & 0.575 \\
\hline Presence of other site infection & $12(27.3)$ & $42(48.8)$ & 0.030 \\
\hline Previous antibiotic usage & $12(27.3)$ & $39(45.3)$ & 0.071 \\
\hline Culture proven pneumonia & $37(84.1)$ & $80(93.0)$ & 0.128 \\
\hline Polymicrobial etiology & $2(4.5)$ & $6(7.0)$ & 0.186 \\
\hline MDR bacteria & $32(72.7)$ & $60(69.8)$ & 0.883 \\
\hline Length of stay before VAP & $12.61 \pm 11.20$ & $14.31 \pm 10.348$ & 0.138 \\
\hline APACHE II score & $16.39 \pm 6.71$ & $16.81 \pm 6.63$ & 0.730 \\
\hline
\end{tabular}

in the regression model. Multiple logistic regression revealed that the risk of inadequate initial $A B$ in $\mathrm{HAP}$ patients was more than twice as large among patients with late-onset HAP $(\mathrm{OR}=2.35$ (95\% CI, 1.05-5.22; $\mathrm{p}=$ 0.037 ) and the risk was also found to be significantly associated with the higher APACHE II score at the onset of HAP (OR $=1.06$ (95\% CI, 1.01-1.12); $\mathrm{p}=0.018)$. In VAP patients; antibiotic usage in the previous three months $(\mathrm{OR}=3.16(95 \% \mathrm{CI}, 1.27-7.81) ; \mathrm{p}=0.013)$ and admission to a surgical unit $(\mathrm{OR}=2.9$ (95\% CI, 1.17 7.19); $\mathrm{p}=0.022$ ) were found to be independent risk factors for inadequate initial $A B$.

Sixty eight (31.2\%) patients out of 218 died in the HAP group and $88(67.7 \%)$ patients died in the VAP group. In the HAP group 95 (43.6\%) patients were admitted to an ICU during their hospital stay and 54 (56.8\%) of these died. The remaining 123 patients were followed in other wards and $14(11.4 \%)$ of these died. The difference was statistically significant $(\mathrm{p}<0.001)$. The outcome measures of patients who did and did not receive adequate initial $A B$ are summarized in Table 6 . No statistically significant difference in crude hospital mortality was observed between the groups in both VAP and HAP (Table 6). The pneumonia related mortality also did not reach statistical significance by day 28 after the diagnosis of pneumonia in either HAP or VAP $[25.2 \%(30 / 119)$ with adequate initial $A B$ versus $39.5 \%(32 / 81)$ with inadequate initial $A B$ in HAP

Table 3 Microorganisms recovered from patients with HAP and VAP

\begin{tabular}{|c|c|c|c|c|c|c|}
\hline \multirow[t]{2}{*}{ Bacteria } & \multicolumn{3}{|c|}{$\operatorname{HAP}(n=103)^{*}$} & \multicolumn{3}{|c|}{$\operatorname{VAP}(n=125)^{*}$} \\
\hline & Adequate $n=49$ & Inadequate $n=54$ & $p$ & Adequate $n=41$ & Inadequate $n=84$ & $\mathrm{p}$ \\
\hline Acinetobacter spp & $8(7.8)$ & $13(12.6)$ & 0.499 & $13(10.4)$ & 37 (29.6) & 0.383 \\
\hline Pseudomonas spp & $10(9.7)$ & $14(13.6)$ & & $9(7.2)$ & $21(16.8)$ & \\
\hline S. aureus & $12(11.6)$ & $7(6.8)$ & & $10(8)$ & $13(10.4)$ & \\
\hline S.pneumoniae & $6(5.8)$ & $5(4.8)$ & & $1(0.8)$ & $5(4)$ & \\
\hline K. pneumonia & $3(2.9)$ & $3(2.9)$ & & $3(2.4)$ & $2(1.6)$ & \\
\hline E.coli & $6(5.8)$ & $5(4.8)$ & & $2(1.6)$ & $4(3.2)$ & \\
\hline Others & $4(3.9)$ & $7(6.8)$ & & $3(2.4)$ & $2(1.6)$ & \\
\hline
\end{tabular}

$\mathrm{n}=$ Number of microorganisms in patient groups. 
Table 4 Antimicrobial agents used in patients with HAP and VAP

\begin{tabular}{|c|c|c|c|c|c|c|}
\hline \multirow[t]{2}{*}{ Empiric antibiotic } & \multicolumn{3}{|c|}{ HAP $(n=218)$} & \multicolumn{3}{|c|}{$\operatorname{VAP}(n=130)$} \\
\hline & $\begin{array}{c}\text { Adequate } \\
(\mathrm{n}=128)\end{array}$ & $\begin{array}{c}\text { Inadequate } \\
(n=90)\end{array}$ & $\mathbf{p}$ & $\begin{array}{l}\text { Adequate } \\
(\mathrm{n}=44)\end{array}$ & $\begin{array}{c}\text { Inadequate } \\
(n=86)\end{array}$ & $\mathbf{p}$ \\
\hline Carbapenems & $31(24.2)$ & $16(17.8)$ & 0.004 & $20(45.5)$ & $18(20.9)$ & $<0.001$ \\
\hline Third generation cefalosporine & $31(24.2)$ & $27(30.0)$ & & $4(9.1)$ & $20(23.3)$ & \\
\hline$\beta$-lactam $+\beta$ - lactamase inhibitor & $35(27.3)$ & $21(23.3)$ & & $14(31.8)$ & $26(30.2)$ & \\
\hline Quinolone & $21(16.4)$ & $16(17.8)$ & & 0 & $10(11.6)$ & \\
\hline$\beta$-lactam in combination with quinolone & $1(0.8)$ & $9(10.0)$ & & 0 & $9(10.5)$ & \\
\hline Aminoglycoside in combination with carbapenem or $\beta$-lactam & $9(7.0)$ & $1(1.1)$ & & $6(13.6)$ & $3(3.5)$ & \\
\hline
\end{tabular}

patients $(\mathrm{p}=0.519)$ (Figure 1$)$ and $75.0 \%(30 / 40)$ with adequate initial $\mathrm{AB}$ versus $71.2 \%(42 / 59)$ with inadequate initial $\mathrm{AB}$ in VAP patients $(\mathrm{p}=0.847)$ (Figure 2)]. In VAP patients median survival time after VAP onset was 13 days with adequate initial $\mathrm{AB}$ and 14 days with inadequate initial $\mathrm{AB}$ (Figure 1). In HAP patients median survival time after HAP onset was 26 days with adequate initial $\mathrm{AB}$ and 22 days with inadequate initial $\mathrm{AB}$ (Figure 2).

\section{Discussion}

Despite numerious studies in the literature, most of our knowledge about the risk factors and prognostic impact of inadequate initial $\mathrm{AB}$ was based on studies of VAP because well-conducted studies involving patients who are not undergoing mechanical ventilation are lacking. Similarly the American Thoracic Society/ Infectious Diseases Society of America evidence-based guidelines for nosocomial pneumonia are mainly based on studies of VAP but it is recommended to treat patients who were not intubated or undergoing mechanical ventilation, in the same manner as those with VAP [3]. Although treatment alternatives are similar, in our study we planned to evaluate the risk factors for inadequate initial $\mathrm{AB}$ and the impact of adequacy

Table 5 Characteristics of culture positive patients with HAP and VAP with regard to the adequacy of empirical antibiotic treatment

\begin{tabular}{|c|c|c|c|c|c|c|}
\hline \multirow[t]{2}{*}{ Characteristics } & \multicolumn{3}{|c|}{ HAP $(n=94)$} & \multicolumn{3}{|c|}{$\operatorname{VAP}(n=117)$} \\
\hline & $\begin{array}{l}\text { Adequate treatment } \\
n=43(\%)\end{array}$ & $\begin{array}{l}\text { Inadequate treatment } \\
n=51(\%)\end{array}$ & $p$ & $\begin{array}{c}\text { Adequate treatment } \\
n=37(\%)\end{array}$ & $\begin{array}{l}\text { Inadequate treatment } \\
\qquad \mathrm{n}=\mathbf{8 0}(\%)\end{array}$ & $\mathrm{p}$ \\
\hline Age (years) & $60.67 \pm 16.04$ & $65.14 \pm 13.75$ & 0.167 & $63.59 \pm 16.65$ & $63.85 \pm 17.07$ & 0.907 \\
\hline Sex (male) & $32(74.4)$ & $37(72.5)$ & 1.000 & $24(64.9)$ & $45(56.3)$ & 0.497 \\
\hline Surgical unit & $9(20.9)$ & $8(15.7)$ & 0.697 & $21(56.8)$ & $25(31.3)$ & 0.015 \\
\hline \multicolumn{7}{|l|}{ Underlying diseases } \\
\hline Diabetes mellitus & $5(11.6)$ & $8(15.7)$ & 0.789 & $5(13.5)$ & $11(13.8)$ & 1.000 \\
\hline COPD & $13(30.2)$ & $10(19.6)$ & 0.341 & $11(29.7)$ & $17(21.3)$ & 0.443 \\
\hline Chronic renal failure & $5(11.6)$ & $4(7.8)$ & 0.727 & $0(0)$ & $3(3.8)$ & 0.551 \\
\hline Congestive heart failure & $4(9.3)$ & $9(17.6)$ & 0.386 & $6(16.2)$ & $13(16.3)$ & 1.000 \\
\hline Cerebrovascular disease & $1(2.3)$ & $9(17.6)$ & 0.019 & $3(8.1)$ & $15(18.8)$ & 0.227 \\
\hline Malignancy & $6(14.0)$ & $9(17.6)$ & 0.838 & $6(16.2)$ & $11(13.8)$ & 0.944 \\
\hline Central venous catheterization & $16(37.2)$ & $22(43.1)$ & 0.710 & $30(81.1)$ & $58(72.5)$ & 0.442 \\
\hline Urinary catheterization & $33(76.7)$ & $37(72.5)$ & 0.820 & $37(100)$ & $78(97.5)$ & 1.000 \\
\hline Late-onset pneumonia & $34(79.1)$ & $46(90.2)$ & 0.223 & $34(91.9)$ & $72(90)$ & 1.000 \\
\hline Acquisition of other site infection & $12(27.9)$ & $11(21.6)$ & 0.637 & $11(29.7)$ & $42(52.5)$ & 0.036 \\
\hline Previous antibiotic usage & $20(46.5)$ & $23(45.1)$ & 1.000 & $11(29.7)$ & $36(45.0)$ & 0.173 \\
\hline MDR bacteria & $29(67.4)$ & $38(74.5)$ & 0.599 & $32(86.5)$ & $60(75)$ & 0.243 \\
\hline Polymicrobial etiology & $1(2.3)$ & $8(15.7)$ & 0.036 & $2(5.4)$ & $6(7.5)$ & 1.000 \\
\hline Length of stay before HAP & $7.6 \pm 4.3$ & $9.18 \pm 5.8$ & 0.194 & $13.89 \pm 11.56$ & $14.88 \pm 10.34$ & 0.313 \\
\hline APACHE I| score & $12.7 \pm 5.83$ & $14.92 \pm 5.83$ & 0.031 & $16.08 \pm 6.94$ & $16.69 \pm 6.72$ & 0.654 \\
\hline Exitus & $16(37.2)$ & $24(47.1)$ & 0.452 & $27(73)$ & $53(66.3)$ & 0.608 \\
\hline
\end{tabular}


Table 6 Outcome of patients who did and did not receive adequate antimicrobial therapy

\begin{tabular}{|c|c|c|c|c|c|c|}
\hline & \multicolumn{3}{|c|}{$\operatorname{HAP}(n=218)$} & \multicolumn{3}{|c|}{$\operatorname{VAP}(n=130)$} \\
\hline & $\begin{array}{c}\text { Adequate } \\
(n=128)\end{array}$ & $\begin{array}{l}\text { Inadequate } \\
(\mathrm{n}=90)\end{array}$ & p & $\begin{array}{l}\text { Adequate } \\
(n=44)\end{array}$ & $\begin{array}{c}\text { Inadequate } \\
(\mathrm{n}=86)\end{array}$ & $\mathbf{p}$ \\
\hline In hospital mortality $(n, \%)$ & $32(25.8)$ & $35(38.9)$ & 0.056 & $32(72.7)$ & $56(65.1)$ & 0.497 \\
\hline Length of total hospital stay & $19.61 \pm 14.40$ & $24.22 \pm 13.70$ & 0.001 & $28.57 \pm 23.66$ & $45.00 \pm 49.30$ & 0.0091 \\
\hline Length of stay after the diagnosis of pneumonia & $12.52 \pm 11.14$ & $15.70 \pm 11.21$ & 0.010 & $16.45 \pm 18.23$ & $30.71 \pm 46.21$ & 0.034 \\
\hline Duration of intubation & & & & $19.11 \pm 19.74$ & $32.14 \pm 49.51$ & 0.050 \\
\hline Resolution of fever and other symptoms & $2.40 \pm 2.91$ & $4.96 \pm 7.79$ & $<0.001$ & $5.70 \pm 5.50$ & $9.09 \pm 10.33$ & 0.044 \\
\hline
\end{tabular}

of initial $\mathrm{AB}$ on the prognosis of patients with HAP and VAP separately.

In this study $66.6 \%$ of patients in VAP and $41.3 \%$ of patients in HAP received inadequate initial $\mathrm{AB}$. The percentage of patients who received inadequate initial $\mathrm{AB}$ is quite variable in the previously published studies and changes from $10 \%$ to $73 \%$ [8-11,13-18]. The knowledge regarding the colonization of patients, the need to limit selection pressure and the sensitivity profile of the suspected pathogens may influence the frequency of inappropriateness of initial $\mathrm{AB}$.

We identified higher APACHE II score and late-onset pneumonia as independent risk factors for inadequate initial $\mathrm{AB}$ for patients with HAP. Although severity indices are not always mentioned in studies regarding the adequacy of $\mathrm{AB}$ of pneumonia, patients with higher severity are considered to be at high risk of poor outcome and they are also likely to be infected by more resistant bacteria $[10,11]$. Similarly late-onset nosocomial pneumonia is caused most frequently by hospital-acquired and often MDR pathogens [20-22]. The potential involvement of more resistant bacteria in the late-onset pneumonia is

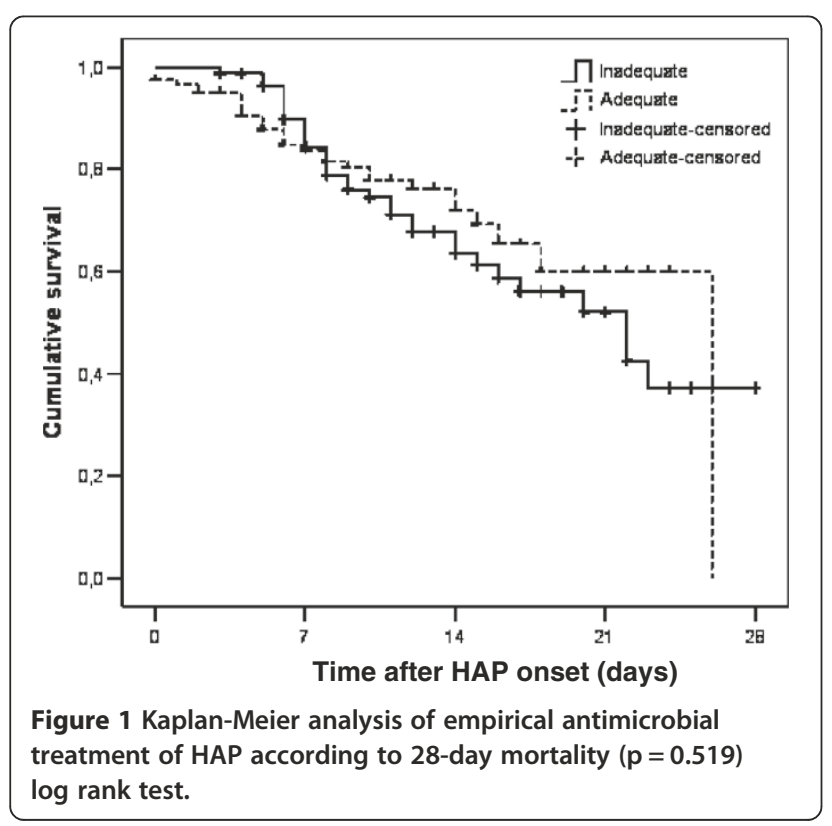

more likely to lead to inadequate treatment with traditional antibiotic regimens $[4,6,8,22]$. However, we did not find such association in late onset pneumonia regarding the adequacy of initial $\mathrm{AB}$ and susceptibility patterns of the isolated pathogens when we performed the analysis in culture positive patients only. This conflicting result may be explained by the distribution of MDR bacteria within the groups. In our study cohort the presence of MDR bacteria was higher in the inadequate treatment arm in HAP patients and this was statistically significant. But this significance could not be shown when only culture positive HAP patients were analyzed. So we may conclude that the causative pathogens in late-onset pneumonia in culture negative HAP patients were resistant to the initial empiric AB. Although the presence of polymicrobial etiology were found to be associated with inadequate initial $A B$ in HAP patients both in general and in the subgroup analysis of the culture positive patients, it was not determined as an independent risk factor. We believe that this may be due to the small number of patients with polimicrobial etiology.

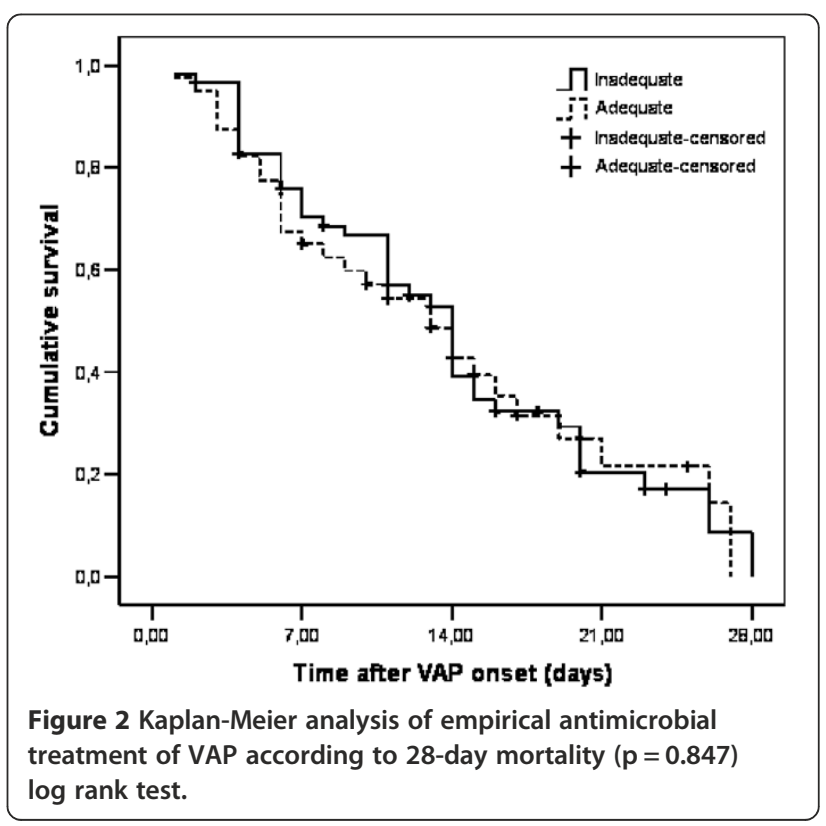


For patients with VAP previous antibiotic usage and admission to a surgical unit were found to be independent risk factors for inadequate $A B$. Previous antibiotic exposure is one of the most evident risk factors for nosocomial infections due to antibiotic-resistant bacteria, and it was reported as an independent risk factor for inadequate $A B$ in most of the previously published studies [6,10,22-24]. "Admission to a surgical ICU" as being a risk factor for inadequate $A B$ is more difficult to explain. The separation of patients into medical and surgical units without identifying the performed surgical procedure may have affected the analysis of risk factors.

In our study cohort, all of the identified risk factors were shown to be indirectly associated with the acquisition of resistant bacteria for both VAP and HAP. However, in contrast to the results of other previously published studies, multivariate analysis showed that, presence of MDR bacteria was not an independent risk factor for both of the groups, [5,8]. This contradictory finding may be due to the MDR Acinetobacter spp. outbreak which had just begun early in the study period in our ICUs. This could also be a possible explanation of high rates of inadequate therapy in our study population in general. We reevaluated the empiric treatment choices after the antibiotic susceptibility profile of the epidemic clone had been identified. For some of the isolates colistin was the only drug of choice but since colistin was unavailable in the market, in Turkey at the time of the study, we were not able to use it as an empirical treatment option. As a result the presence of MDR bacteria was high in both of the treatment groups and the difference regarding the frequency of MDR bacteria between groups did not reach statistical significance. In patients with HAP, presence of MDR bacteria was associated with inadequate $\mathrm{AB}$ but in the final multivariate model this was not significant. Although we have included both culture positive and culture negative patients in the risk factor analysis, the impact of presence of MDR bacteria did not change when the analysis was performed in culture proven patients only.

In this study, we were not able to find any statistically significant difference in mortality rates between patients who received inadequate initial $A B$ and patients who received adequate initial $A B$ for both $\mathrm{HAP}$ and VAP. Available studies evaluating the impact of empirical $A B$ have produced conflicting results; some found positive correlation between adequate empirical $\mathrm{AB}$ and survival, whereas others did not [8-15]. These contradictory results are probably ascribable to differences in patients and pathogens responsible for pneumonia; since in the studies those found higher mortality rates when $A B$ was inadequate, the patients who received inadequate $A B$ were the ones with pneumonia caused by the most difficult to treat microorganisms $[5,11]$. In a prospective study of patients with late-onset VAP; it was reported that infection due to non-fermenting gram-negative bacilli was the most important predictor of in-hospital mortality [22]. These pathogens were also the most common isolates in our study. However, the frequency of non-fermenting gram-negative bacilli in the inadequate and adequate $A B$ groups was not significantly different and this may have affected the survival results. Another reason may be the difference in the definition of adequate $A B$ as in some studies adequate $A B$ was defined as $A B$ with a favorable clinical response and in others it is described as microbiological recovery of susceptible organisms to the empirical antibiotic regimen. In the present study we used both of these definitions; in culture positive patients the adequacy of antibiotics were defined according to the results of the antimicrobial susceptibility testing whereas in culture negative patients clinical response to the empiric antibiotic regimen was taken into consideration. However the assosciation between the adequacy of the initial $A B$ and survival did not change when the analysis was performed in culture positive patients only for both VAP and HAP.

In our study cohort although we could not find a positive correlation between adequate initial antimicrobial therapy and survival, we showed a significant increase in ICU length of stay, duration of mechanical ventilation and a prolonged clinical resolution in the inadequate $A B$ group for both VAP and HAP. Other researchers also reported an increased length of stay and increased duration of mechanical ventilation when initial $A B$ was inadequate in comparison with adequate $\mathrm{AB}[6,10]$. Only in one study evaluating the outcome of patients with VAP, length of ICU and hospital stays were found to be similar in patients who did and did not receive adequate initial $\mathrm{AB}$ [11]. For patients receiving adequate $\mathrm{AB}$, it was reported that clinical resolution of pneumonia usually begins during the first several days of treatment $[6,25]$. Our results were correlated with the literature, besides we showed a significant prolongation of the clinical resolution when the initial antibiotic therapy was inadequate.

The present study has several limitations. Its retrospective design is a limitation, since it was not possible to conduct an accurate analysis of any changes in the empirical $A B$ regimens. On the other hand, the retrospective feature could have been an advantage as the prescription of initial $\mathrm{AB}$ was not influenced by a prospective evaluation during which a large spectrum initial $A B$ could have been chosen. Another limitation is the impact of specific pathogens on the adequacy of initial $\mathrm{AB}$ and survival could not be performed because stratification into smaller groups would complicate entry in the logistic regression model, as each group would have a very small number of cases. 


\section{Conclusions}

In the present study, late-onset pneumonia and APACHE II score at the onset of HAP were found to be independent risk factors for inadequate initial $\mathrm{AB}$ in patients with HAP whereas previous antibiotic usage and admission to a surgical unit were found to be associated with inadequate initial $A B$ in VAP. Our data suggests that the risk factors for inadequate initial $\mathrm{AB}$ were indirectly associated with the acquisition of resistant bacteria for both VAP and HAP. Moreover, patients who received inadequate initial $\mathrm{AB}$ with VAP or HAP, had a longer duration of hospital stay and an increased clinical resolution time. Our findings support the importance of investigating the local ecology by active surveillance cultures and follow-up of susceptibility patterns to establish adequate empirical $\mathrm{AB}$. Therefore, consideration should be given to the empirical use of a broaderspectrum antibiotic that has not previously been administered, especially for the coverage of resistant gramnegative bacteria in order to minimize the occurrence of inadequate $\mathrm{AB}$.

\section{Competing interests}

The authors declare that they have no competing interests.

\section{Authors' contributions}

NP participated in study design and in data collection and interpretation, performed the statistical analysis and drafted the manuscript. HA and NO participated in study design, data collection and interpretation. DA participated in study design and revised the manuscript for important intellectual content. FC participated in data collection and interpretation. FK performed the statistical analysis and helped to draft the manuscript. GC revised the manuscript for important intellectual content. All authors read and approved the final manuscript.

\section{Financial support}

None reported.

\section{Author details \\ 'Departments of Infectious Diseases and Clinical Microbiology, School of Medicine, Zonguldak Bulent Ecevit University, Zonguldak, Turkey. ${ }^{2}$ Department of Infectious Diseases and Clinical Microbiology, Antalya Teaching and Research Hospital, Antalya, Turkey. ${ }^{3}$ Department of Microbiology and Clinical Microbiology, Zonguldak Bulent Ecevit University, Zonguldak, Turkey. ${ }^{4}$ Deparment of Biostatistics, Zonguldak Bulent Ecevit University, Zonguldak, Turkey.}

Received: 12 November 2011 Accepted: 24 August 2012 Published: 24 October 2012

\section{References}

1. Torres A, Ferrer M, Badia JR: Treatment guidelines and outcomes of hospital-acquired and ventilator-associated pneumonia. Clin Infect Dis 2010, 51(Suppl 1):48-53.

2. American Thoracic Society: Hospital-acquired pneumonia in adults: diagnosis, assessment of severity, initial antimicrobial therapy and preventive strategies (consensus statement). Am J Respir Crit Care Med 1996, 153:1711-1725.

3. American Thoracic Society Documents: Guidelines for the management of adults with hospital-acquired, ventilator associated, and healthcare-associated pneumonia. Am J Respir Crit Care Med 2005, 171:388-416.
4. Kollef $\mathrm{MH}$ : Inadequate antimicrobial treatment: an important determinant of outcome for hospitalized patients. Clin Infect Dis 2000 31(Suppl 4):131-138

5. Niederman MS: Use of broad-spectrum antimicrobials for the treatment of pneumonia in seriously ill patients: maximizing clinical outcomes and minimizing selection of resistant organisms. Clin Infect Dis 2006, 42(Suppl 2):72-81.

6. Kollef MH, Sherman G, Ward S, Fraser VJ: Inadequate antimicrobial treatment of infections: a risk factor for hospital mortality among critically ill patients. Chest 1999, 115:462-474.

7. Luna CM, Aruj P, Niederman MS, Garzón J, Violi D, Prignoni A, Ríos F, Baquero S, Gando S: Appropriateness and delay to initiate therapy in ventilator-associated pneumonia. Eur Respir J 2006, 27:158-164.

8. Teixeira PJ, Seligman R, Hertz FT, Cruz DB, Fachel JM: Inadequate treatment of ventilator-associated pneumonia: risk factors and impact on outcomes. J Hosp Infect 2007, 65:361-367.

9. Leroy O, Meybeck A, d'Escrivan T, Devos P, Kipnis E, Georges H: Impact of adequacy of initial antimicrobial therapy on the prognosis of patients with ventilator-associated pneumonia. Intensive Care Med 2003, 29:2170-2173.

10. Dupont H, Mentec H, Sollet JP, Bleichner G: Impact of appropriateness of initial antibiotic therapy on the outcome of ventilator-associated pneumonia. Intensive Care Med 2001, 27:355-362.

11. Clec'h C, Timsit JF, De Lassence A, Azoulay E, Alberti C, Garrouste-Orgeas M, Mourvilier B, Troche G, Tafflet M, Tuil O, Cohen Y: Efficacy of adequate early antibiotic therapy in ventilator-associated pneumonia: influence of disease severity. Intensive Care Med 2004, 30:1327-1333.

12. Heyland DK, Cook DJ, Griffith L, Keenan SP, Brun-Buisson C: The attributable morbidity and mortality of ventilator-associated pneumonia in the critically ill patient. Am J Respir Crit Care Med 1999, 159:1249-1256.

13. Torres A, Aznar R, Gatell JM, Jiménez P, González J, Ferrer A, Celis R, Rodriguez-Roisin R: Incidence, risk, and prognosis factors of nosocomial pneumonia in mechanically ventilated patients. Am Rev Respir Dis 1990, 142:523-528.

14. Rello J, Gallego M, Mariscal D, Soñora R, Valles J: The value of routine microbial investigation in ventilator-associated pneumonia. Am J Respir Crit Care Med 1997, 156:196-200.

15. Kollef MH, Ward S: The influence of mini-BAL cultures on patient outcomes: implications for the antibiotic management of ventilatorassociated pneumonia. Chest 1998, 113:412-420.

16. Alvarez-Lerma F: Modification of empiric antibiotic treatment in patients with pneumonia acquired in the intensive care unit. ICU-Acquired Pneumonia Study Group. Intensive Care Med 1996, 22:387-394.

17. Luna CM, Vujacich P, Niederman MS, Vay C, Gherardi C, Matera J, Jolly EC: Impact of BAL data on the therapy and outcome of ventilator-associated pneumonia. Chest 1997, 111:676-685.

18. Sanchez-Nieto JM, Torres A, Garcia-Cordoba F, El-Ebiary M, Carrillo A, Ruiz J, Nuñez ML, Niederman M: Impact of invasive and noninvasive quantitative culture sampling on outcome of ventilator-associated pneumonia: a pilot study. Am J Respir Crit Care Med 1998, 157:371-376.

19. Garner JS, Jarvis WR, Emori TG, Horan TC, Hughes JM: CDC definitions for nosocomial infections. Am J Infect Control 1988, 16:128-140.

20. Fleming CA, Balaguera HU, Craven DE: Risk factors for nosocomial pneumonia. Focus on prophylaxis. Med Clin North Am 2001, 85:1545-1563.

21. Trouillet JL, Chastre J, Vuagnat A, Joly-Guillou ML, Combaux D, Dombret MC, Gibert C: Ventilator-associated pneumonia caused by potentially drug-resistant bacteria. Am J Respir Crit Care Med 1998, 157:531-539.

22. Kollef $M H$, Silver $P$, Murphy DM, Trovillion E: The effect of late-onset ventilator-associated pneumonia in determining patient mortality. Chest 1995, 108:1655-1662.

23. Kollef $M H$ : Ventilator-associated pneumonia. A multivariate analysis. JAMA 1993, 270:1965-1970.

24. Rello J, Ausina V, Ricart M, Castella J, Prats G: Impact of previous 
antimicrobial therapy on the etiology and outcome of ventilatorassociated pneumonia. Chest 1993, 104:1230-1235.

25. Dennesen PJ, van der Ven AJ, Kessels AG, Ramsay G, Bonten MJ: Resolution of infectious parameters after antimicrobial therapy in patients with ventilator-associated pneumonia. Am J Respir Crit Care Med 2001, 163:1371-1375

doi:10.1186/1471-2334-12-268

Cite this article as: Piskin et al:: Inadequate treatment of ventilatorassociated and hospital-acquired pneumonia: Risk factors and impact on outcomes. BMC Infectious Diseases 2012 12:268.

\section{Submit your next manuscript to BioMed Central} and take full advantage of:

- Convenient online submission

- Thorough peer review

- No space constraints or color figure charges

- Immediate publication on acceptance

- Inclusion in PubMed, CAS, Scopus and Google Scholar

- Research which is freely available for redistribution 